\title{
Factors Affecting the Language Learning of EFL Students through ABC Model: A Cross Cultural Analysis
}

\author{
SARIANI, MUTIA EL KHAIRAT \\ Politeknik Negeri Padang, Sumatera Barat, 2500, Indonesia \\ E-mail: sarianipasnieyahoo.com, mutiaelkhairatpnp@gmail.com
}

\begin{abstract}
This research concerns on a breakthrough in enhancing the learning by having more understanding between the students and lecturers. It is in basis of one experience is un-comparable to another experience as each has their own uniqueness. Regarding to this matter, the use of ABC's model, as has been experienced by other studies, is considered significant to reach the goal of this research. This study applies qualitative method based on the descriptive data, and are analyzed by using cultural analysis of differences and similarities taken from the 'Venn Diagram' between autobiographies of the participants and biographies of their partner. The participants were randomly chosen from fresh year students at English Department, State Polytechnic of Padang. They are from different family backgrounds; middle up family level and low family level. Derived from the ABC analysis conducted, there are five factors found which are considered to affect EFL students in learning process; those are passion in learning English, learning process, motivation, facilities, and circumstances.
\end{abstract}

Keywords - ABC Model; Diagram Venn; Factors

\section{INTRODUCTION}

Language learning has been an important aspect in human life since a long time ago. It is clear that language is a tool of communication. So, the use of language will affect the communication of people in their life. It is proved by the increase of foreign language learners in many places, especially English learners. In Indonesia, particularly, the English learners, in formal or informal education, come from different backgrounds and must follow the learning system which has been organized by the government or institution. Furthermore, they practically only learn the language in class because they learn it in their own country. Learning a foreign language in the mother tongue (L1) speaker's environment with different background makes some learners experience difficulties to apply it in everyday life. It means that, the effectiveness of learning process cannot be achieved since the learners have varied circumstances and they still use their L1 outside the class.

There are many teaching methods that have been developed related to this problem. The educators even have utilized advance information and technology to help them in learning process. In fact, the learners still have difficulties in completing and mastering the language. Even though they have been treated with the same material and method, but their accomplishment is different. This phenomenon sometimes affects the learners in the learning process and the instructor in the evaluating process. In the end, this problem will also alter the language acquisition of learners. It means that the instructor should be creative in finding the method and adapt it with the condition of the learners.

Similarly, this problem occurs on the students of Politeknik Negeri Padang (PNP), West Sumatera, Indonesia who learn English as one of the compulsory subjects. The students come from many places in West Sumatera and 
even outside the province which means they have different background, such as family, culture, financial, education, and social situation. Even though there are many methods of assessments that have been treated by the lecturers, the results are still not equal. According to Hatch (1983), language acquisition is related to subconscious process including implicit learning, informal learning, and natural learning. It clearly describes that, language learning and language acquisition process cannot be separated from many aspects of the learners' life. Due to the situation in PNP in the present, there should be a further study which can solve this problem so there will be improvement of language acquisition in the future.

One of applicable ways to solve this situation is by applying ABC's model of cultural understanding and communication. $\mathrm{ABC}$ itself stands for Autobiography, Biography, and CrossCultural Analysis. This model was developed by Patricia Ruggiano Schmidt \& Claudia Finkbeiner the key of this model basically is "Know thyself, understand others" (Schmidt \& Finkbeiner, 2006). It refers to the process of finding differences and similarities of people by concerning on their autobiography, biographies, and a cross-cultural analysis. Its goal is to increase the respect towards different background of others and observe someone's self-image and cultural self-concept. It will be interesting to implement this model for students in PNP and to analyse the relationship between their background and their difficulties in learning language, especially English, through their autobiography, biography, and cross-cultural analysis. It can help students to know their selves and teacher to overcome the obstacles in teaching English in the future.

This study significantly aims at finding the factors that influence students' difficulties of PNP in learning English. As the students' English score is yet satisfying, it is expected that the students will increase their awareness towards their selfimage and their friend's condition when studying English inside and outside the class. It will also affect their interaction with classmates and increase their willingness in studying English. Furthermore, the finding of this study also can be used to help lecturers in understanding the condition of students and creating new method in teaching English subject for students based on their backgrounds. Therefore, it can improve the students' score and develop their language acquisition.

Based on the background and significance of this study, the hypothesis of this research is the varied personal backgrounds of PNP students which have big impact and influence towards their language acquisition. Due to the fact that, the students have different language acquisition of learning even though they have been treated with the same method and material. This phenomenon leads the hypotheses whether their background can affect their process in learning language or there is no possibility of its influence towards their ability in mastering a language, particularly English.

\section{RESEARCH METHOD}

\section{A. RESEARCH FRAMEWORK}

This study applies the qualitative method as it was based on the descriptive data (MacKey \& Gass, 2005), and it was relevant to the study on language acquisition which has been conditioned by social, cultural, and situational factors (Dornyei, 2007). To put it more simply, the highlight of this study was the in-depth selfanalysis of cultural differences referred to the researcher's subjective interpretation of the data obtained (Dornyei, 2007), which was visualised into a diagram of differences and similarities.

\section{1) METHOD STEP}

The cultural analysis derives from the analysis made of the differences and the similarities between the autobiographies of the participants and the biographies of their partners (Schmidt \& Finkbeiner, 2006). The first step was writing the autobiography where the participant exploring themselves deeper about their self-image and cultural self-concept in learning English as English for Foreign Language (EFL). By writing up their autobiography they could also increase their awareness of personal beliefs and attitudes (Banks, 1994).

The second step was the biography. For this step one participant interviewed another participant who was from different family background. The interview was recorded and the questions provided was in the form of semi structured one. The questions were set based on the personal beliefs, attitude, and tradition values of their partner's in learning English. This setting was significant as it could be a guidance for the 
participants to dig much information from their partner, while at the same time it allowed stretchability while the interview happened (McDonough \& McDonough, 1997) to get more information (MacKey \& Gass, 2005).

Cross-cultural analysis was the last step taken. It was the depth analysis and was conducted by the researcher by drawing it into a "Venn Diagram" to have a clear vision of key components chosen for the comparison. The diagram was two intersecting circles which extracted from autobiography and biography (Schmidt \& Finkbeiner, 2006, p. 5).

\section{2) PROCEDURES}

The sequences that have been performed were:

a. The students from the different background of family; low level and originated from the village, and moderate level originated from the city were chosen randomly based on their willingness to participate in this study. Then they were assigned to work in partner; one student from low level and originated from the village worked with one student from moderate level and originated from the city (partnership).

b. Next, each student wrote his/ her autobiography (A) by using their L1. Then within their partnership, he/ she interviewed each of their partner for biography (B). The interview was organized without the presence of the researcher in order to avoid the anxiety, distress occured during the process. It was in the form of video and audio recording for the duration about 5 to 10 minutes.

c. The interview was conducted throughout the operating hours from Monday through Friday at the convenient time of the students. It was carried out based on the set of semi structured questions which has been written before by the researchers and in their L1, to have more quality and quantity of the data provided (MacKey \& Gass, 2005).

d. Finally the cultural analysis (C) was analyzed by the researcher from the differences and similarities spotted within autobiography and biography of each pair.

\section{3) CONFIDENTIALITY}

There was 'Human Consent' form to all participants and signed to make sure that they had a freedom to be in or withdraw from the study at their convenience.

\section{B. SAMPLE AND POPULATION}

The population was coming from one single location: fresh year students at English Department, PNP. As most of qualitative research deal with fewer participants (MacKey \& Gass, 2005 ) to assist the researcher to work more labourintensive, thus, this study takes the sample referred to 'Typical sampling' strategy (Dornyei, 2007). This study appointed the participants whose experience was relevant to the study and also fitted the time frame and resources of the researchers and the students.

Here was those whose experience in learning foreign language which is English, and arrived from two different backgrounds of family; low level and originated from the village, and moderate level originated from the city. There was ten participants to be interviewed and were chosen randomly and based on their willingness; five participants from low level and originated from the village, and another five from moderate level and originated from the city.

\section{DATA COLLECTING}

Consequently, the data gathering took the two steps out of the three steps from the ABC's Model. The first data was obtained from the autobiography (A), and the second one was from biography (B):

a. Autobiography: there was ten autobiography which has been translated and summarized into English by the researcher. It was conducted before the video taping of the interview being held.

b. Biography: there was ten video-taped biography which have been transcribbed by each pair and then translated into English by the researcher.

Preliminary, both A and B phases used the students' L1 in order to make them feel at ease to express themselves. Even though the video recording in the biography step was time consume as the data should be transcribed, this technique could deliver an accurate and detailed record of 
actual language data (McDonough \& McDonough, 1997, p. 186).

\section{DATA ANALYSIS}

The analysis was based on the data obtained from A and B's of the students. It was analyzed through similarities and differences they have as required by the 'Cultural Venn Iceberg' diagram, established by Finkbeiner \& Schmidt (2006). The differences made referred to the explanation of each partnership's feeling, i.e., "Why did am I feeling spiritful to learn English even though I know many people said it is difficult?. By having this diagram analysis, the data could be sort out, and elaborated taken from detailed and significant information for the visible and invisible promises.

The concern was more on differences and similarities that could be seen on the surface, which were named differences above (DA) and similarities above (SA), and invisible similarities and differences which were named differences below (DB) and similarities below (SB) (Finkbeiner, 2009). The first perspective of the analysis was the view on one student, and the second one was those told by other students. Finally, these two perspectives were compared referred to cross cultural analysis which came from the differences and the similarities.

\section{THEORETICAL BACKGROUND}

\section{A. LANGUAGE LEARNING}

As a matter of fact, the language uttered by someone shows their identity as part of a community and culture they live. As stated by Fanany (2015) the language spoken derives from self-thought and perception which is used to interact with others. Mostly they origin from the same area and speak the same language and has the same view on looking at things.

Regarding to this perspective, within a community, one tends to learn a language where they physically, socially and psychologically comfort. The feeling of knowing each other, the reason behind their togetherness, and what they want to achieve become effective factors of the language learning (Woodward, 2009). The feeling of comfort among others who we are familiar with can directly become the significant factor in the case of learning a language.

\section{1) CULTURE AND LANGUAGE LEARNING}

Brown (1994, cited in Finkbeiner, 2008) described culture as "'glue' that binds a group of people together" (Brown, 1994, cited in Finkbeiner, 2008). It happens where people who have similarity in any aspects which have been learned through their life time will gather and develop their own culture. In addition, Hofstede \& Hofstede (2005) pointed out that they considered culture as a collective phenomenon. For this reason there should be separated explanation between human nature and individual's personality or character.

Meanwhile Levine \& Adelman (1993) argued that as culture is a shared background which comes from many parts in life, such as common language and communication style customs, beliefs, attitudes and values, behaviour and interaction of an individual are from the influence of culture which yet exposed. It is like an iceberg, as some are recognized and some are stayed hidden within one self when they interact with the others or when they express themselves. Like the visualization occurred in the iceberg, this hidden part of the culture might create cross cultural difficulties among others.

Correspondently, Weaver (1983) agreed that this culture's iceberg only can be seen from one existing horizon for about one-seventh and the rest is non observable. This means that there are many parts of this iceberg which are still in hidden dimension. For this matter, Finkbeiner (2009) then came up with strategies and efficient tools to enable an individual to manage and to navigate the unknown region within oneself out of the known one. She highlighted that "Human beings are multi-facetted and often non-predictable in their actions. There are always components that remain unknown to the self as well as to others" (Finkbeiner, 2009, p. 152).

In a language learning, cultural values and beliefs play significant role (Finkbeiner, 2009), as in many cases the way of one person pursue their learning, particularly language are shaped on how they brought up in their family and community. How necessary for them to continue their education regardless their family level in the society. Kumaradivelu (2008) argued that "In performing such a central function, culture provides individuals and groups of individuals with psychological structures that guide various 
aspects of their life" (Kumaradivelu, 2008, p. 10). Therefore by appreciating their own cultural identity they will appreciate more diversity which come on the way of their learning setting. In agreement to this, Schmidt (1999) stated that how valuable it is when students' differences, whether physical, academic, or cultural, are recognized" (Schmidt, 1999, p. 336).

\section{2) ENGLISH FOR FOREIGN LANGUAGE (EFL) LEARNING}

English for Foreign Language (EFL) as one of the foreign languages learned in formal education in Indonesia has been becoming widely implemented. Mostly EFL is studied in English speaking countries and will be used when the speaker will use it with any other English speakers in the world. The difference between EFL and English as a Second Language, the latest is learned in the target country where the speaker lives in this target community and this target language (English) is needed in order to communicate with others in this target country.

As a foreign language which has a total different from their L1, thus the attitude and enthusiasm of its learners are necessary and have profound effect on their achievement. As Harmer (2007) stated that in behaviourist theory, there are three stages of learning that one should have; stimulus, response, and stimulus (p. 51). Besides the result the learners receive from their learning, their behaviour on learning itself also derives from the culture which has shaped them; family and/ or community.

We need to take into account on how this EFL learners perception of English. By having a good opinion of this language and the rationale of learning it, it can motivate them indirectly to put much effort on learning it. In addition, they can also challenge and extend their ideas of this language and the future that they will have by acquiring it (Woodward, 2009).

\section{B. ABC'S OF CULTURAL UNDERSTANDING AND COMMUNICATION}

This study took the ABC model which has been adapted by Dr. Claudia Finkbeiner after her meeting with Patricia Ruggiano Schmidt at World Congress in Reading, Jamaica in 1998. Finkbeiner then decided to collaborate with Schmidt to reshape this model as they believe the new version can have valuable difference in their field as teachers educators and preparing better teachers for present and future (Schmidt \& Finkbeiner, 2006). Subsequently, this adaptation model is the latest concerns more to bring multiple perspectives on intercultural learning where language learning is a part of them. It has been proven by researchers, teachers, and students within the process of their teaching, learning, and appreciation of differences (Schmidt, 2006).

According to Schmidt \& Finkbeiner (2016, p. 2) the ABC's term comes from the first initial of Autobiography (A), Biography (B), and the Cross cultural analysis (C) of the two mentioned previously. The A for autobiography is a welldocumented key life event on someone which can be part of their education, family, religious tradition, recreation, victories, defeats, and others. Whereas the B for biography is another version of well-documented relevant life events of someone else obtained through an interview with this person. It is in a democratic interview setting where the questions are mostly semi structured which opens for elaboration of each question. Meanwhile the $\mathrm{C}$ for cross cultural analysis focuses on the study of those life events occurred in autobiography and biography based on differences and similarities occurred. They argue that the critical literacy is a theoretical concept where it sees literacy teaching and a learning as one thing which is never neutral.

As highlighted by Finkbeiner (2001, 2003, 2005 cited in Schmidt \& Finkbeiner, 2006) in her researches, she found much valuable information from her respondents who were university students about their life learning on language, particularly English as Foreign Language. Implementing this model to the students brought a strong connection to the whole classroom as it can make them building a highly cooperation to each other. Moreover Finkbeiner (2005) stated that by asking the students who became the respondents to write their autobiography and to do the interview for biography in their L1, there is going to be rich data obtained as they feel at ease to express themselves. She valued that by using the language that one masters completely demonstrated how cultural understanding can be useful for language learning and worthwhile communication.

Even though Osetek (2006) embraced ABC's Model of Cultural Understanding and Communication as well, the analysis was wider 
than on one-self-awareness of life events. The study emerged the participation of family perspective as the active member of their child's educational experience as the decision maker for their child's school setting. The result showed that educational process of a child is shaped by society and social class educational expectation (p. 44). By all means, it stated that one experience is incomparable to another experience as each has their own uniqueness. In other words the worth having experience for one might be different meaning to another.

\section{IV.RESULT AND DISCUSSION}

\section{A. FINDING}

The findings perceived are in the form of Autobiography (A) and Biography (B) which are two out of three stages in the ABC Cultural Analysis.

\section{1) AUTOBIOGRAPHY}

The writing for the autobiography was assigned to the students as the preliminary data collecting. The writing was first in their L1 and then translated by the researchers into English without changing the meaning. For validity of the translation, the result then showed to the students to come to the agreement of the translation. Beforehand, the students have been told that they were free to change the translation whenever they thought that the result was not coherent to what they have written.

\section{2) BIOGRAPHY}

The writing for Biography (B) stage was conducted right after the autobiography one. The writing derived from the interview's result which was conducted by the students in pair work. One student from the low level and originated from the village worked with one student from moderate level and originated from the city. First the pair had to interview their partner and after that they wrote down the result of their interview. This stage was conveyed by using their L1 in order to make the interviewee felt at ease in expressing their thought. Then the results were translated as well by the researchers into English, by having approval and agreement of the learners for their content.

\section{B. CROSS CULTURAL ANALYSIS}

The $\mathrm{C}$ part was the analysis between similarities and differences which was found on the autobiography' results and biography one taken from all participants; middle up family level and low family level. Even though they have known for quite a time, it seems that there is still reluctance among them especially in speaking class. In this class, they were expected to work in pair or group meaning that they had to completely blend themselves so they can finish the task given. The analysis made was also referred to the following Cultural Venn Iceberg diagram.

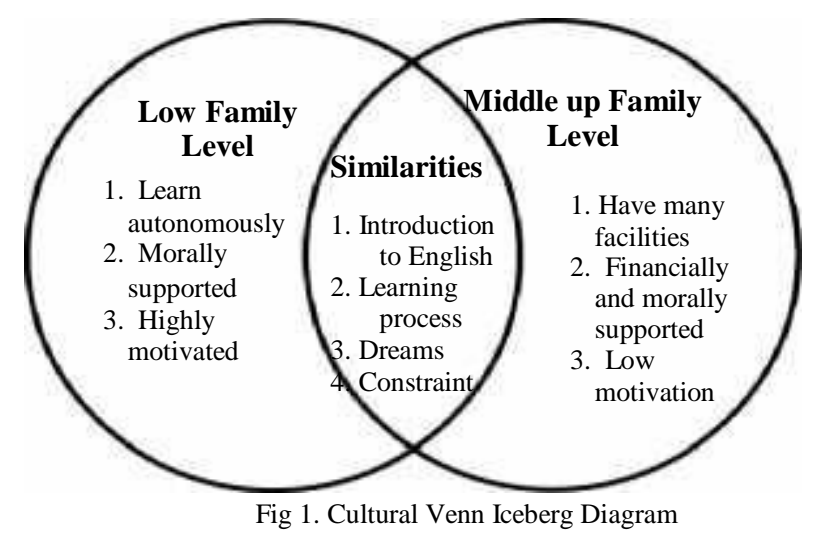

1) SIMILARITIES

Based on autobiography, biography which was completed after conducting the interview, the students basically had many similarities in English learning process. All the students speak Indonesian language as they second language, although they live in different regions with various accents in their mother tongue. Besides, there are some students who are from outside West Sumatera, since their families move to other cities in other provinces like Jakarta or Pekanbaru. However, their parents mostly are originally Minang people. English is their foreign language (EFL) and they learn it because of many reasons. Some similarities regarding to their English learning process could be elaborated as follow.

First, the students have known English since their early age. Due to curriculum of formal education which required the children to start the school at the age of seven (7) for elementary school, all students have been learning English since they went to study. Even, some of them have been introduced to English from kindergarten. Their family also had a big role in acquainting them to English whether by teaching them or accidentally introduced it through songs, movies, or books in English. The students realized since the beginning how important English for their life 
was. It was their first step on how they finally became loving English and learning it for years.

Second, the students had the same English learning process. Mostly, the students learned English by listening to English songs and watching English movies. For the songs, even some of them have known English songs since the early age which was affected by their family members who love to hear the songs. They used to search the lyrics and memorize it. They learned English pronunciation by listening to the songs over and over again. They also got new vocabulary by finding the words meaning of the lyrics through dictionary. For the movies, they watched them while reading the subtitle and then tried to copy the actor or actress on how they pronounced the sentences. It really helped them in learning English as in fact students in teen-age usually tend to love singing a song and watching movie rather than reading textbook to learn English.

Fourth, the students admitted that English had a big role if they wanted to get a better job after graduating from universities. Mostly they said that English is international language, therefore everyone in the world understands and needs it as tool of communication. Job vacancy also requires someone who is competent in English to be the employee. As an additional, they believe that by mastering English they could make their dream come true to travel overseas. They assumed that if they speak English well then there won't have any problem regarding to communicating with a stranger. Through this analysis, it was proven that they had the same aims to learn English; to get a good job and to travel around the world in the future.

Last, the analysis indicated that these students had similar constraints in learning English that was the lack of partnership for exercising. They said that it was quite difficult for them to find partner for practicing the knowledge they had outside the class room. The students contended that they could not practice their English since there were no friends or partner to do a conversation. Actually, this is one of many problems relating to English' learners learning process. They have got theories in formal education at school but they cannot apply this knowledge after the school time. It is equitable since English is not their second language but their foreign language. Their mother tongue is Minang language and their second language is Indonesian. It can be said that their circumstances do not accommodate them to use English for daily communication. Thus having someone who had the same passion in English to become their partner to practice their knowledge could not be easily done. In the end, this challenge indirectly affected their language acquisition.

Then those similarities from the autobiography which was written by the students, and the biography which was constructed by their friends after the interview session were compiled. Even though they come from different family backgrounds, referring to this compilation it could be seen that they had many similarities regarding to their English acquaintance process.

\section{2) DIFFERENCES}

As Finkbeiner (2009) stated that in a language learning, cultural values and beliefs play significant role, it refers to a conclusion that language learners are affected by the values which they believe. Even though these students had many similarities in their language learning process, but they were brought up from different families and community. Kumaradivelu (2008) also said that aspects of someone's life are affected by their cultures which lead to central function performance of individual or group. They had different life stories and problems in achieving their education and knowledge, particularly English. These conditions led to some differences which were faced by them in language learning process since the differences on their backgrounds; middle up and low family level.

First, the students who came from low family level acquired their knowledge autonomously at home by repeating the lessons from school by themselves. Their family, mostly, had difficulties in financial to afford their education informally. Mostly these students got scholarship to continue their education into university level. They tried to improve their knowledge, particularly English, by reading textbook which provided by school and discussed with friend or their sibling after school. On the other hand, students who came from middle up family level obtained more facilities than the lower family one. Mostly, they went to English course and received facilities from their family, 
such as English books, comics, novels and computer. Their families were economically capable to provide these kinds of facilities for their children in order to support them in learning English.

Second, related to their economic condition, students who came from lower family level were only supported by their family mostly on motivation to learn English not on financial. Their parents knew that English would be useful for their children since English is international language. They encouraged their children to learn English emotionally, such as suggestion and motivation. The students admitted that the motivation received has been affecting their spirit to learn this language more. On the contrary, students who lived in middle up family level were supported all the way around financially and emotionally. They were facilitated by English course, English books, printed and electronics dictionary, and personal computer. The motivation they accepted from their parents to learn English more came from the understanding that how important English was very for their future.

Last, the analysis shown that the students who came from low family level were highly motivated in learning English compared to students from middle up family level. They had passion in learning even though their families were not good financially. Even, in the data could be found that one student was supported by her aunt triggered by her high motivation in learning. Her aunt brought her to overseas; Singapore so that she could practice her English in the real life and bought her English novel to support her effort in learning. Mostly, the students who were from this family level chose English as their major because they loved English and wanted to be able to use it well. They dreamt to have a better future which could change their life financially by mastering English.

On the other hand, students who came from middle up family level chose English as their major because they did not have other choices. Some of them had desire to enter other departments, like engineering or accounting, but they were not accepted in these departments. So, basically they went to English Department because of the suggestion from their family or their teacher. It was because these people knew that they were good in English and would be a good chance for them to master English instead of other departments. Their family financial condition made them comfort and had lack of motivation to learn more in order to get a better life. Different from low level one, these middle up level family students learned English because they only wanted to have higher education for their life.

\section{FACTORS WHICH AFFECT LANGUAGE LEARNING OF EFL STUDENTS THROUGH ABC MODEL; CROSS CULTURAL ANALYSIS}

The analysis addressed to the students' autobiography and biography by using ABC's model found that there were some factors which affected the students' language learning, especially English for their foreign language (EFL), in acquiring its knowledge. Department for Education and Employment cited in Wilden (2006) highlighted that through providing pupils with insights into cultural differences and opportunities to relate these to their own experience and to consider different cultural and linguistic traditions, attitudes and behaviour. Similar to what has been stated above, this study pointed out that own experience, linguistic traditions, attitudes and behaviour did take major role in the students' EFL acquisition. In this context passion in learning English, learning process, motivation, facilities, and circumstances were factors discovered which affected the language learning.

\section{Passion in learning English}

Here, through the analysis, passion became one of factors which could affect the language acquaintance of students. The data shown that the students who had passion in learning English had high spirit to know more about English in and outside the class. Some students admitted that they had passion in learning English from early age because of various reasons. Their family members or their hobbies toward song and movie were some reasons why they loved English. In the end, it affected their willingness to learn English as an EFL students. Being an EFL student was not an easy thing for them since they faced many constraints and problems related to their learning process, such as grammar, vocabulary, accent, practice and many more. So, having passion and willingness were considered effectively affected their language acquaintance. 


\section{Learning process}

The process in acquiring the language also took an important factor which affected the learning process of foreign language. Since they are EFL students, so they have put some efforts to find a fun way to learn this language. Within this study, it could be seen that most of students made use of their hobbies as the media for learning English, for example singing, watching movies or reading novel. This method was practical for them, as what they told in the interview, to help them in learning English. They used to learn English from song's lyrics. They worked on finding the meaning of the lyrics and then learned the pronunciation by listening to the song repeatedly. After that, they sang the song by themselves to practice their pronunciation.

Some others learned English by watching movie through the meaning of the words from its subtitle, carefully listened to it, and imitated to the way of the actor or the actress talked in the movie. They learned daily spoken sentences from the movie even English slang language. Indirectly, this learning process has helped them to enjoy in acquiring their English knowledge rather than what they got from their formal school. Some students admitted that English class was a kind of boring and monotonous one. Therefore, it could be said that learning process in this analysis could affect the EFL students' language acquaintance.

\section{Motivation}

The fact that English is international language and one of requirements which always asked by the employer make the students put English as one of their compulsory skill. Derived from the $\mathrm{A}$ and $\mathrm{B}$ model stages that has been conducted in this study, the analysis drawn that the students dreamt to have a good job after graduating from university. The data clarified that their family suggested them to master English in order to have a good job in their future.

Their dream to work in a big company and paid with dollars was for the reason to help their family financially and to make their family proud of them. Besides, they also assumed that by mastering English, they could easily travel around the world and communicate with foreigners. The dream was also to bring their family overseas and did not have to think about language barrier anymore since they could speak English well. Mostly, these students had the same thought about
English and what would they get if they could speak English well. Indeed, they were motivated by these thoughts to learn English more and to grasp their dreams.

\section{Facilities}

Similarly, facilities played important role in EFL students learning process as well. The analysis showed that their language acquaintance has been affected by the family's support financially and emotionally. The students which were being investigated in this study needed not only suggestion from their parents but also facilities that they could use for their learning process. Both of these aspects had the same effect towards their acquaintance. Those who were supported by their family and school turned out to have more confidence in learning something. Whereas, those who were from low level family only wished to get more facilities in learning English like attending English course, having compatible dictionaries and internet connection, or English books.

\section{Circumstances}

Bear upon, circumstances was the last point resulted from the analysis. Here, the students lived in a circumstance where there were less of people who could speak English in daily conversation. Thus, they had to manage establishing their own way in order to improve and to enrich their knowledge about English. As a matter of fact EFL could not be utilized fully in Indonesia. It became a big constraint for students since they were not able to notice a circumstance which applied English as a communication tools.

It was such a hard thing to do to find a partner for practicing English outside their formal education. It was in agreement that "A child lives in many worlds. Home, family, school, neighbourhood, and society shape the contours of childhood and adolescence" (Edward et al. as cited in Schmidt \& Finkbeiner, 2006, p. 21). Having the knowledge received from school could not guarantee that they were able to implement it in their world outside the classroom. By all means, using their mother tongue to speak with their family and neighbour, and their second language (Bahasa Indonesia) to speak with their friends were carried forward. Thus, they could not get into English while watching television or listening to the radio for English programs. These made them chose national channel for TV and radio instead, 
and had no significant progress on their ability and acquaintance in learning English.

\section{CONCLUSION}

\section{A. CONCLUSION}

Through the data taken on the Autobiography and the B (Biography), it can be gathered rich information in the Cultural Analysis (C) the similarities and the differences occurred within the sample. Nevertheless the participants chosen come from similar culture and behaviour, they are divided into two financial background; middle up family level and low family level. Hence, these backgrounds influence much on their learning and acquire language like their passion in learning, motivation and dream, support/ facilities from their close people in life and the constraints they experience.

By all means, it is clearly seen that this $\mathrm{ABC}$; cultural analysis model has shaped the thought of the participants in looking at their friends, particularly in their language learning process. It is broaden the understanding of their lecturers as well in addressing their students not only during their time in the class room but also outside the class. Positively this ABC model provides good insight for the language learning and is manageable to implement in the language classroom.

\section{B. SUGGESTION}

In regard to the study conducted on the $\mathrm{ABC}$ Model; A Cultural Analysis on learners of EFL at English Department classes, there are several factors acquired which consider can affect the process of the learning itself. In light of the advantages resulted having this ABC Model applied, there would be significant as well to take this model into English subject classes on other departments beside English. It is to address the question whether this $\mathrm{ABC}$ model can also possibly assist both the students and the lecturers to come to such deeply understanding of each in their learning process. Therefore, there won't be any judgments arise among the students on their way of learning and/ or on the way they acquire the English knowledge. Moreover, this model is expected to be favorable for the lecturers to realize and understand that each of their students has different ways of learning and acquiring knowledge which have been shaped by many factors. By having these thought, hopefully there would be much progress obtained on learning EFL.

\section{REFERENCES}

[1] Banks, J. A. (1994). An Introduction to Multicultural Education Allyn and Bacon Inc., 160 Gould St., Needham Heights, MA 02194.

[2] Dornyei, S. (2007). Research Methods in Applied Linguistics. Oxford: Oxford University Press.

[3] Fanany, I. (2015). Language and Well-Being. International Seminar on Language and Arts (ISLA)-4, Proceeding, 4, 1-11.

[4] Finkbeiner, C. (2009). Using 'Human Global Positioning System' as a Navigation Tool to the Hidden Dimension of Culture. In A. Feng, M. Byram, M. Fleming (Eds), Becoming Interculturally Competent through Education and Training. Bristol: Multilingual Matters.

[5] Harmer, J. (2007). The Practice of English Language Teaching. Pearson Education: Edinburgh, UK.

[6] Hatch, Evelyn Marcussen. (1983). Psycholinguistics A Second Language Perspective. Cambridge: Newbury House Publishers.

[7] Levine, D. R. \& Adelman, M. B. (1993). Beyond Language. CrossCultural Communication. Prentice Hall Inc: New York.

[8] Kumaradivelu, B. (2008). Cultural Globalization and Language Education. Yale: Yale University.

[9] Mackey, A. \& Gass, M.S. (2005). Second Language Research. Mahwah, New Jersey: Lawrence Erbaulm Associates, Inc.

[10] McDonough, J. \& McDonough, S. (1997). Research Methods for English Language Teachers. Great Britain: Arnold.

[11] Osetek, J. M. (2006). A Journey Toward Making A Positive. P. R. Schmidt and C. Finkbeiner (Ed.), ABC's Cultural Understanding and Communication. National and International Adaptations: $A$ Journey Toward Making A Positive (pp. 43-72). Greenwich, Conneticut: IAP-Information Age Publishing, Inc.

[12] Schmidt, P.R. (1999). Know Thyself and Understand Others: Connecting home and school. Language Arts, 76 (4), 332-340.

[13] Schmidt, P. R. \& Finkbeiner, C. (2006). What is the ABC's of Cultural Understanding and Communication. P. R. Schmidt and C. Finkbeiner (Ed.), ABC's Cultural Understanding and Communication. National and International Adaptations: What is the $A B C$ 's of Cultural Understanding and Communication (pp. 1-18). Greenwich, Conneticut: IAP-Information Age Publishing, Inc.

[14] Weaver, G.R. (1993). Understanding and coping with cross-cultural adjustment stress. In M. Paige (ed), Education for the Intercultural Experience, Second edition. Yarmouth, ME: Intercultural press, $137-167 \mathrm{M}$.

[15] Wilden, E. (2006). The ABC Online. Using Voice Chats in a Transnational Foreign Language Teacher Exchange, ABC's Cultural Understanding and Communication. National and International Adaptations: What is the ABC's of Cultural Understanding and Communication (pp. 189-211). Greenwich, Conneticut: IAP-Information Age Publishing, Inc.

[16] Woodward, T. (2009). Planning Lessons and Courses. Cambridge: Cambridge Press 